\title{
An increase in mean platelet volume after admission is associated with higher mortality in critically ill patients
}

\author{
Fernando G Zampieri ${ }^{1,2,3^{*}}$, Otavio T Ranzani ${ }^{1}$, Viviane Sabatoski ${ }^{1}$, Heraldo Possolo de Souza ${ }^{2}$, Hermes Barbeiro ${ }^{2}$, \\ Luiz Monteiro Cruz da Neto ${ }^{1}$, Marcelo Park ${ }^{1}$ and Fabiano Pinheiro da Silva ${ }^{2}$
}

\begin{abstract}
Background: Platelet activation and consumption are common in critically ill patients and are associated with poorer prognosis. Mean platelet volume is a simple surrogate for platelet activation, with higher MPV being associated with worse clinical condition on a large array of clinical diagnoses. We therefore aimed to investigate associations between changes in platelet count and mean platelet volume (MPV) with prognosis and inflammatory cytokine values in critically ill patients.

Methods: This study prospectively included 84 critically ill patients. Patients were stratified into four groups according to proportional changes in MPV $\left(\Delta \mathrm{MPV}_{24 h}\right)$ and platelet count $\left(\Delta \mathrm{Plat}_{24 h}\right)$ in the first 24 hours after admission. Mortality between groups was compared using the $X^{2}$ test. Logistic regression was performed using hospital mortality as outcome and Simplified Acute Physiology Score (SAPS 3), $\triangle \mathrm{Plat}_{24 \mathrm{~h}}$ and $\triangle \mathrm{MPV}_{24 \mathrm{~h}}$ as covariates. Concentrations of the following inflammatory mediators were measured using Miliplex ${ }^{\oplus}$ technology: IL1 $\beta$, IL6, IL8, IL10, epidermal growth factor, vascular endothelial growth factor, TNFa and IFNa. Cytokine concentrations were compared between groups using the Kruskal-Wallis test with Bonferroni correction.
\end{abstract}

Results: Patients in whom MPV increased and platelet count decreased had higher mortality rates (46\%). According to logistic regression, $\triangle \mathrm{MPV}_{24 \mathrm{~h}}$ was independently associated with increased mortality (OR 1.28 per 1\% increase; $95 \% \mathrm{Cl} 1.08$ to 1.48). No strong associations between inflammatory mediators and changes in MPV and platelet count were found.

Conclusion: An increase in MPV after admission to an ICU is independently associated with higher hospital mortality.

Keywords: Platelet; Critical illness; Inflammation; Endothelial activation

\section{Background}

Inflammation is ubiquitous during the course of critical illness, regardless of its cause [1]. One of the hallmarks of inflammation, endothelial dysfunction, is involved in the pathway of organ dysfunction and may be associated with platelet activation and consumption $[2,3]$. Therefore, it is not surprising that absolute platelet count and

\footnotetext{
* Correspondence: fgzampieri@gmail.com

${ }^{1}$ Intensive Care Unit, Emergency Medicine Discipline, Hospital das Clínicas, University of São Paulo, São Paulo, Brazil

${ }^{2}$ Laboratory of Medical Investigation 51 (LIM 51), Faculty of Medicine,

University of São Paulo, São Paulo, Brazil

Full list of author information is available at the end of the article
}

trends in this variable are reportedly to be strongly associated with prognosis in critically ill patients $[4,5]$.

Inflammatory and thrombotic conditions may also alter platelet size, which can be detected on routine blood cell analysis by evaluation of mean platelet volume (MPV) [6-8]. Furthermore, the MPV is affected by aging of platelets and varies according to the balance between production and destruction. In several inflammatory clinical conditions, the degree of inflammation and changes in MPV appear to be correlated; however, the impact of this is controversial [6-8]. A prospective study of neonatal sepsis concluded that septic newborns have greater MPVs than those without sepsis, whereas a prospective study in adults suggested that low 
platelet volumes are associated with poorer prognoses in septic adults [6-8]. Furthermore, because there is a strong inverse correlation between platelet count and MPV in healthy individuals, trends in platelet count should be considered when evaluating MPV [8].

This study aimed to evaluate the impact of changes in MPV and platelet count in the first 24 hours after ICU admission on hospital mortality in an unselected sample of critically ill patients. Our initial hypothesis was that both an increase in MPV and decrease in platelet count in the first 24 hours after ICU admission would be associated with higher hospital mortality in critically ill patients. As secondary endpoints, we sought to evaluate the association between concentrations of several cytokines on admission and changes in MPV and platelet count.

\section{Methods}

\section{Study design}

This study was a sub-analysis of a prospective observational study that aimed to evaluate the inflammation and acid-base status of critically ill patients. The study was approved by Hospital das Clinicas' Ethics Committee (registry number 1207/09). Exclusion criteria for the study were: age < 18 years; pregnancy; history of HIV with criteria for acquired immunodeficiency syndrome; current diagnosis of cancer on chemotherapy; previous diagnosis of acute or chronic hematologic cancer; use of chronic immunosuppressant medication other than steroids. Low platelet count was not an exclusion criterion. All patients or their legal surrogates provided written informed consent for inclusion in the study.

\section{Patient sample}

Of the 87 patients enrolled in the main study from February 2010 to January 2012, 84 had valid measurements of MPV on admission to the ICU and were included on this analysis. Relevant clinical variables and illness severity (as assessed by the Simplified Acute Physiology Score (SAPS 3) score [9]) were recorded in all patients.

\section{Blood sample and measurements}

Blood for the performed measurements analysis was drawn from patients on the morning after ICU admission and placed in tubes with ethylenediamine tetraacetic acid until sample processing. In our institution, the mean time between drawing of blood samples and start of sample processing is approximately one hour. In our ICU, platelet analysis is performed daily as part of routine care. Platelet number and MPV were measured using automated machines (Sysmex XT2000i, Sysmex, Kobe, Japan). When aggregated platelets were present on the automated report, a manual check was performed as part of the routine laboratory procedures at our institution. Percentage change in MPV in the first 24 hours after admission $\left(\triangle M P V_{24 h}\right)$ was defined as:

$$
\begin{aligned}
\Delta M P V_{24 h}= & \left(\left[M P V_{\text {day } 2}-M P V_{\text {admission }}\right] / M P V_{\text {admission }}\right) \\
& \times 100
\end{aligned}
$$

where $M P V_{\text {day2 }}$ is the MPV value for the sample collected 24 hours after admission and $M P V_{\text {admission }}$ is the MPV value for that collected on ICU admission. Changes in platelet count in the first 24 hours after admission $\left(\Delta\right.$ Plat $\left._{24 \mathrm{~h}}\right)$ were calculated as percentage in a similar way:

$$
\begin{aligned}
\Delta \text { Plat }_{24 h}= & \left(\left[\text { Plat }_{\text {day } 2}-\text { Plat }_{\text {admission }}\right] / \text { Plat }_{\text {admission }}\right) \\
& \times 100
\end{aligned}
$$

where Plat ${ }_{\text {day2 }}$ is platelet count on the day following ICU admission and Plat ${ }_{\text {admission }}$ is the platelet count on admission.

Concentrations of inflammatory mediators (cytokines and chemokines) were measured using Miliplex ${ }^{\oplus}$ technology (Merck, Genese Diagnostics, Darmstadt, Germany), a multiplex method for cytokine analysis. Miliplex-assessed concentrations of the following cytokines are included on this analysis: IL1 $\beta$, IL6, IL8, IL10, epidermal growth factor (EGF), vascular endothelial growth factor (VEGF), TNF $\alpha$ and IFN.

\section{Statistical analysis}

Data were tested for normality using the KolmogorovSmirnov test or Shapiro-Wilk test, as appropriate. Continuous normal data were compared using Student's $t$-test or analysis of variance. Continuous non-parametric data were compared with the Mann-Whitney test or Kruskal-Wallis test, as appropriate. Fisher's exact test or $\chi^{2}$ test was used for dichotomous variables. A $P$-value $<0.05$ was considered significant. Bonferroni or Tukey post hoc correction was used for multiple comparisons, if needed. When multiple dichotomous comparisons were performed, the $P$-value was adjusted using Keppel-modified Bonferroni correction:

$$
\text { Significant } P-\text { value }:\left[1-\{1-0.05\}^{\mathrm{df}}\right] / \mathrm{df}
$$

where df is number of degrees of freedom [10]. Patients were categorized into the following four groups according to $\triangle \mathrm{MPV}_{24 \mathrm{~h}}$ and $\triangle \mathrm{Plat}_{24 \mathrm{~h}}$ : decrease in platelet count and decrease in MPV $\left(\Delta \mathrm{Plat}_{24 \mathrm{~h}} \leq 0 / \Delta \mathrm{MPV}_{24 \mathrm{~h}} \leq 0\right.$ group); decrease in platelet count and increase in MPV $\left(\Delta \mathrm{Plat}_{24 \mathrm{~h}} \leq 0 / \Delta \mathrm{MPV}_{24 \mathrm{~h}}>0\right.$ group $)$; increase in platelet count and decrease in MPV $\left(\Delta\right.$ Plat $_{24 h}>0 / \Delta M P V_{24 h} \leq 0$ group); and increases in both platelet count and MPV $\left(\Delta\right.$ Plat $_{24 \mathrm{~h}}>0 / \Delta \mathrm{MPV}_{24 \mathrm{~h}}>0$ group $)$.

Two different approaches were employed to evaluate the impact of changes in $\Delta \mathrm{MPV}_{24 \mathrm{~h}}$ and $\Delta \mathrm{Plat}_{24 \mathrm{~h}}$ on hospital mortality. First, mortality was compared between the aforementioned four groups. Second, logistic regression was performed using hospital mortality as the outcome of interest and SAPS 3 score, $\Delta \mathrm{MPV}_{24 \mathrm{~h}}$ and $\Delta \mathrm{Plat}_{24 \mathrm{~h}}$ 
as predictors. Because platelet count and MPV may be correlated, interactions between $\Delta \mathrm{MPV}_{24 \mathrm{~h}}$ and $\Delta \mathrm{Plat}_{24 \mathrm{~h}}$ were included in the model. We assessed collinearity between variables through measurement of variance inflation factor (VIF). A stepwise selection method was then performed to remove variables from the model. The results of the final model were further confirmed in a bootstrap analysis on 10,000 replications. We planned to evaluate the discriminative capability of hospital mortality for the model obtained from linear regression and SAPS 3 score through a receiver operating characteristics (ROC) curve and computation of the area under curve (AUC). The ROC curves for SAPS 3 and for the model obtained were compared using DeLong's test. Calibration was evaluated through Hosmer-Lemeshow test and through a calibration plot obtained after 10,000 bootstrap replications. Because platelet count may reach its nadir up to four days after ICU admission, another logistic regression analysis was performed comparing changes in MPV and platelet count on the fifth day of ICU stay $\left(\Delta M P V_{\text {day5 }}\right.$ and $\triangle$ Plat $\left._{\text {day5 }}\right)$ with admission values; the fifth day values were calculated similarly to $\triangle \mathrm{MPV}_{24 \mathrm{~h}}$ and $\Delta \mathrm{Plat}_{24 \mathrm{~h}}$.

Cytokine concentrations were also compared between the four patient groups. Associations between admission $\mathrm{MPV}, \triangle \mathrm{MPV}_{24 \mathrm{~h}}$, admission platelet count and $\Delta \mathrm{Plat}_{24 \mathrm{~h}}$ in the whole sample and concentrations of each of the measured cytokines were evaluated by linear regression.

The association between platelet count and MPV at admission and between $\Delta \mathrm{MPV}_{24 \mathrm{~h}}$ and $\Delta \mathrm{Plat}_{24 \mathrm{~h}}$ was also evaluated by linear regression analysis.

All analyses were performed using $\mathrm{R}$ project software (www.r-project.org) version 2.15.2 and Sigmaplot version 12.0 (Systat Software, California, USA).

\section{Results}

In all, data for 84 patients were studied (Table 1). One patient died on the day of admission and, therefore, did not have data necessary for calculating $\triangle M P V_{24 h}$ and $\Delta$ Plat $_{24 \mathrm{~h}}$. Forty-eight percent of the study patients were admitted because of sepsis. The most common sources of infection were lungs (thirteen patients), intravascular catheter (five patients), bloodstream (five patients), urinary tract (four patients) and abdomen (three patients). The commonest reasons for admission of non-septic patients were acute cardiogenic pulmonary edema (nine patients), ischemic stroke (five patients), exacerbation of chronic pulmonary obstructive disease (three patients) and acute subarachnoid hemorrhage (three patients). Only three patients were admitted after elective surgery (two colectomies and one nephrectomy); all surgical patients survived. No patients required extracorporeal membrane oxygenation or intraaortic balloon pump. During the study time window, renal replacement therapy (RRT) was required in 24 patients; continuous hemofiltration with citrate region anticoagulation was the initial method used in all hemodynamic unstable patients (fourteen patients); of those, six were converted to the intermittent method after hemodynamic stabilization. The ten remaining that were hemodynamically stable at initiation of RRT were treated with intermittent dialysis. Heparin was used in intermittent dialysis at the discretion of the consulting nephrology team.

The numbers of patients in each group according to platelet evaluation were as follows: 24 (29\%) patients in the $\Delta$ Plat $_{24 \mathrm{~h}} \leq 0 / \Delta M P V_{24 \mathrm{~h}} \leq 0$ group; 26 (31\%) in the $\Delta \mathrm{Plat}_{24 \mathrm{~h}} \leq 0 / \Delta \mathrm{MPV}_{24 \mathrm{~h}}>0$ group; $22(27 \%)$ in the $\Delta$ Plat $_{24 \mathrm{~h}}>0 / \Delta \mathrm{MPV}_{24 \mathrm{~h}} \leq 0$ group and $11(13 \%)$ in the $\Delta$ Plat $_{24 \mathrm{~h}}>0 / \Delta M P V_{24 \mathrm{~h}}>0$ group. The general characteristics of all study patients (stratified as survivors and non-survivors), as well as MPV and platelet count values at admission and on the first three days of ICU stay, are shown in Table 1.

Platelet counts at 24 and 48 hours after admission were lower in non-survivors. MPVs were similar between survivors and non-survivors at each time point evaluated. Both $\triangle \mathrm{MPV}_{24 \mathrm{~h}}$ and $\Delta \mathrm{Plat}_{24 \mathrm{~h}}$ were associated with mortality according to univariate analysis. Platelet count was negatively associated with MPV at admission $\left(\beta=-3.12 ; P<0.001 ;\right.$ model $\left.r^{2}=0.16\right)$. There was a significant but weak linear association between $\triangle M P V_{24 h}$ and $\Delta$ Plat $_{24 \mathrm{~h}}\left(\beta=-0.04 ; P=0.015\right.$; model $\left.\mathrm{r}^{2}=0.05\right)$.

Mortality was higher for patients in the $\Delta \mathrm{Plat}_{24 \mathrm{~h}} \leq 0$ / $\Delta \mathrm{MPV}_{24 \mathrm{~h}}>0$ group (46\%) than for those in the $\Delta \mathrm{Plat}_{24 \mathrm{~h}} \leq$ $0 / \Delta \mathrm{MPV}_{24 \mathrm{~h}} \leq 0(20 \%)$ and $\Delta \mathrm{Plat}_{24 \mathrm{~h}}>0 / \Delta \mathrm{MPV}_{24 \mathrm{~h}} \leq 0(14 \%)$ groups $(P=0.025$ and 0.015 , respectively). Numbers of survivors and non-survivors in all four groups are shown in Figure 1.

According to logistic regression analysis after stepwise selection, only SAPS 3 (odds ratio (OR) 1.05 per each point increase; $95 \% \mathrm{CI} 1.01$ to 1.09 ) and $\triangle \mathrm{MPV}_{24 \mathrm{~h}}(\mathrm{OR}$ 1.28 per $1 \%$ increase; $95 \%$ CI 1.08 to 1.48 ) were associated with higher hospital mortality. Neither $\Delta \mathrm{Plat}_{24 \mathrm{~h}}$ nor the interaction between $\Delta \mathrm{MPV}_{24 \mathrm{~h}}$ and $\Delta \mathrm{Plat}_{24 \mathrm{~h}}$ were associated with increased hospital mortality. Confidence intervals after bootstrap analysis were 1.01 to 1.10 for SAPS 3 and 1.04 to 1.56 for $\triangle M V_{24 h}$. VIF between SAPS 3 and $\triangle M P V_{24 h}$ was low (1.06). Density plots for $\triangle \mathrm{MPV}_{24 \mathrm{~h}}$ in survivors and non-survivors are shown in Figure 2. A plot for hospital death probability constructed from logistic regression and $\triangle \mathrm{MPV}_{24 \mathrm{~h}}$ values is shown in Figure 3. A three-dimensional plot of the regression plane of hospital mortality and SAPS 3 and $\mathrm{MPV}_{24 \mathrm{~h}}$ values is shown in Figure 4. The model obtained had a non-statistically significant higher AUC when compared to SAPS 3 alone $(0.79 ; 95 \%$ CI 0.67 to 0.91 versus $0.70,95 \%$ CI 0.58 to 0.83 ) (Figure 5 ). Both the model and SAPS 3 were calibrated according to HosmerLemeshow test $(P=0.60$ for the model and $P=0.32$ for 
Table 1 Characteristics of included patients

\begin{tabular}{|c|c|c|c|c|}
\hline & $\begin{array}{l}\text { All patients } \\
(n=84)\end{array}$ & $\begin{array}{l}\text { Survivors } \\
(n=60)\end{array}$ & $\begin{array}{l}\text { Non-survivors } \\
(n=24)\end{array}$ & $P$ \\
\hline Age, mean (SD) & $50.3(17.3)$ & $50.3(16.4)$ & $50.4(19.5)$ & 0.972 \\
\hline Male sex, n (\%) & $45(53 \%)$ & $31(52 \%)$ & $14(58 \%)$ & 0.755 \\
\hline SAPS 3 score, median (IQ) & $52(41.75 ; 64)$ & $48.5(39.5 ; 58.75)$ & $60.5(52 ; 71.75)$ & 0.002 \\
\hline SOFA score, median (IQ) & $5(2 ; 8.25)$ & $4(2 ; 7)$ & $9(5 ; 11.25)$ & $<0.001$ \\
\hline Admission due to sepsis, $\mathrm{n}(\%)$ & $41(48)$ & $24(40)$ & $17(70)$ & 0.020 \\
\hline Vasopressors at admission, n (\%) & $23(27)$ & $11(18)$ & $12(50)$ & 0.007 \\
\hline Need for renal replacement therapy, n (\%) & $24(28)$ & $12(20)$ & $12(50)$ & 0.013 \\
\hline \multicolumn{5}{|l|}{ Comorbidities, n (\%) } \\
\hline Heart failure & $20(23)$ & $17(28)$ & $3(12)$ & 0.209 \\
\hline Diabetes & $23(27)$ & $16(27)$ & $7(29)$ & 0.974 \\
\hline Hypertension & $44(52)$ & $34(57)$ & $10(42)$ & 0.316 \\
\hline Myocardial infarction & $7(8)$ & $6(10)$ & $1(4)$ & 0.662 \\
\hline Stroke & $10(12)$ & $5(8)$ & $5(20)$ & 0.220 \\
\hline Cancer & $3(3)$ & $2(3)$ & $1(4)$ & 0.642 \\
\hline Rheumatic disease & $3(3)$ & $1(1)$ & $2(8)$ & 0.402 \\
\hline Cirrhosis & $4(5)$ & $2(3)$ & $2(8)$ & 0.685 \\
\hline Child-Pugh A & $2(2)$ & $1(2)$ & $1(4)$ & 0.909 \\
\hline Child-Pugh B/C & $2(2)$ & $1(2)$ & $1(4)$ & 0.909 \\
\hline Dementia & $0(0)$ & $0(0)$ & $0(0)$ & - \\
\hline COPD & $3(3)$ & $2(3)$ & $1(4)$ & 0.642 \\
\hline Chronic kidney disease & $16(20)$ & $12(20)$ & $4(17)$ & 0.965 \\
\hline Creatinine, mg/dL (SD) & $1.2(0.81 ; 2.6)$ & $1.14(0.79 ; 2.17)$ & $1.61(0.87 ; 2.85)$ & 0.592 \\
\hline Lactate, mmol/L (IQ) & $1.56(1.11 ; 2.13)$ & $1.50(1.11 ; 1.91)$ & $1.72(1.19 ; 3.72)$ & 0.197 \\
\hline Albumin, g/dL & $2.92(0.70)$ & $3.20(0.65)$ & $2.45(0.59)$ & $<0.001$ \\
\hline Hemoglobin, g/dL & $11.0(2.32)$ & $11.4(2.20)$ & $10.1(2.43)$ & 0.038 \\
\hline Leukocyte count, units $/ \mathrm{mm}^{3}$ & $11,480(7,458 ; 15,970)$ & $11,480(7,615 ; 14,180)$ & $11,090(6,072 ; 20,310)$ & 0.940 \\
\hline Platelet count at admission, $10^{3}$ units $/ \mathrm{mm}^{3}$ & $184.5(138.5 ; 262.2)$ & $192.5(147.5 ; 262.2)$ & $156(119.5 ; 254.5)$ & 0.149 \\
\hline Mean platelet volume at admission, $\mathrm{fL}$ & $10.8(10.2 ; 11.5)$ & $10.9(10.2 ; 11.7)$ & $10.8(10.1 ; 11.2)$ & 0.516 \\
\hline Platelet count at 24 hours, $10^{3}$ units $/ \mathrm{mm}^{3 a}$ & $184(132.5 ; 265.5)$ & $190(143.2 ; 273.2)$ & $139(115 ; 204)$ & 0.031 \\
\hline Mean platelet volume at 24 hours, $\mathrm{fL}^{\mathrm{a}}$ & $11(10.1 ; 11.6)$ & $11.0(10.0 ; 11.6)$ & $11.0(10.3 ; 11.6)$ & 0.511 \\
\hline Platelet count at 48 hours, $10^{3}$ units $/ \mathrm{mm}^{3 b}$ & $188(131 ; 276)$ & $198(144 ; 293.7)$ & $136.5(99.2 ; 215.8)$ & 0.040 \\
\hline Mean platelet volume at 48 hours, $\mathrm{fL}^{\mathrm{b}}$ & $11.1(10.2 ; 11.7)$ & $11.0(10.1 ; 11.6)$ & $11.2(10.6 ; 11.8)$ & 0.333 \\
\hline Platelet count at 72 hours, $10^{3}$ units $/ \mathrm{mm}^{3 \mathrm{c}}$ & $188(133 ; 263)$ & $208.5(142.5 ; 280.8)$ & $146(96 ; 229)$ & 0.093 \\
\hline Mean platelet volume at 72 hours, $\mathrm{fL}^{\mathrm{c}}$ & $11.0(10.3 ; 11.7)$ & $10.6(10.2 ; 11.7)$ & $11.3(10.7 ; 11.7)$ & 0.097 \\
\hline$\Delta \mathrm{MPV}_{24 h}, \%^{\mathrm{a}}$ & $0(-1.68 ; 2.41)$ & $-0.81(-1.80 ; 1.87)$ & $2.04(0 ; 6.01)$ & 0.005 \\
\hline$\Delta P L A T_{24 h}, \%^{a}$ & $-4.27(-12.71 ; 8.83)$ & $-2.52(-11.74 ; 8.82)$ & $-6.18(-24.84 ; 5.85)$ & 0.032 \\
\hline
\end{tabular}

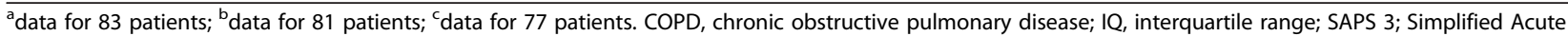
Physiology Score; SOFA score, Sequential Organ Failure Assessment score.

SAPS 3). However, calibration plot shows that the addition of MPV to SAPS 3 score reduces systematic errors in prognostication in the whole range of probabilities (Figure 6, panels A and B). The secondary logistic regression analysis included 77 patients and SAPS 3 score, $\triangle \mathrm{MPV}_{\text {day5}}$, and $\triangle \mathrm{Plat}_{\text {day5. }}$ According to this analysis, only $\triangle \mathrm{MPV}_{\text {day5 }}$ (OR 1.12 per $1 \%$ increase; $95 \%$ CI 1.02 to 1.22 ) was associated with increased hospital mortality.

There was no difference in admission cytokine concentrations between the four studied groups (Table 2). 


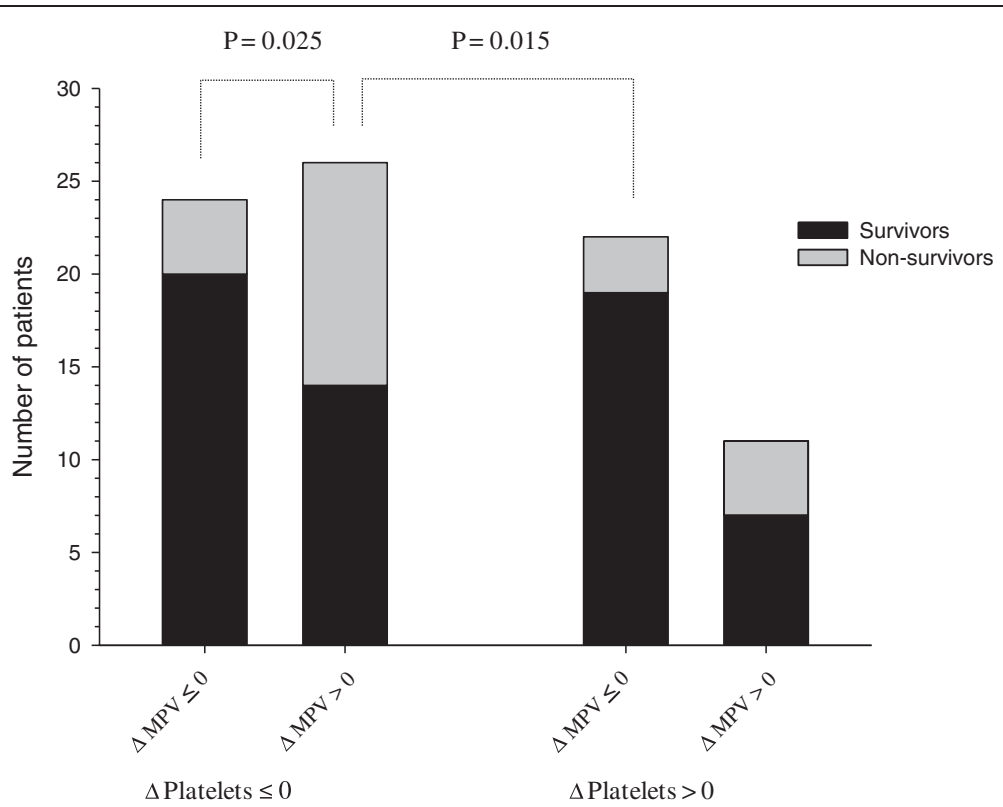

Figure 1 Number of survivors and non-survivors categorized according to variations in platelet count and mean platelet volume (MPV) $\left(P=0.037\right.$ among the four subgroups, $X^{2}$ test). Corrected $P$-value according to Keppel's modified Bonferroni correction: 0.044 .

\section{Discussion}

Our study has two important findings. First, despite having similar MPV values on admission, non-survivors had higher $\triangle M P V_{24 h}$ than did survivors. Patients with decreased platelet counts and increased MPVs at 24 hours had the highest mortality rates of all patient groups. Second, according to logistic regression analysis, only higher $\triangle M V_{24 h}$ values and SAPS 3 scores were associated with increased mortality; changes in platelet count in the first 24 hours had no impact on short-term prognosis. The addition of $\triangle M P V_{24 h}$ to SAPS 3 tended to improve the discriminative capacity of SAPS 3 score, although the difference did not reach statistical significance. Nevertheless, calibration of SAPS 3 score was improved when $\triangle M P V_{24 h}$ was added to the model, with important reduction of systematic errors in prognostication.

MPV is a useful prognostic marker in myriad medical conditions, including ischemic heart disease, infective endocarditis and cerebral infarction [11-13]. Only a few studies have assessed MPV in critical illnesses. Four of these, case series performed in the 1980s and 1990s, highlighted that sepsis is associated with increased MPV [14-17]. More recently, in a larger prospective study, Oncel et al. also reported high MPVs in septic newborns [7].

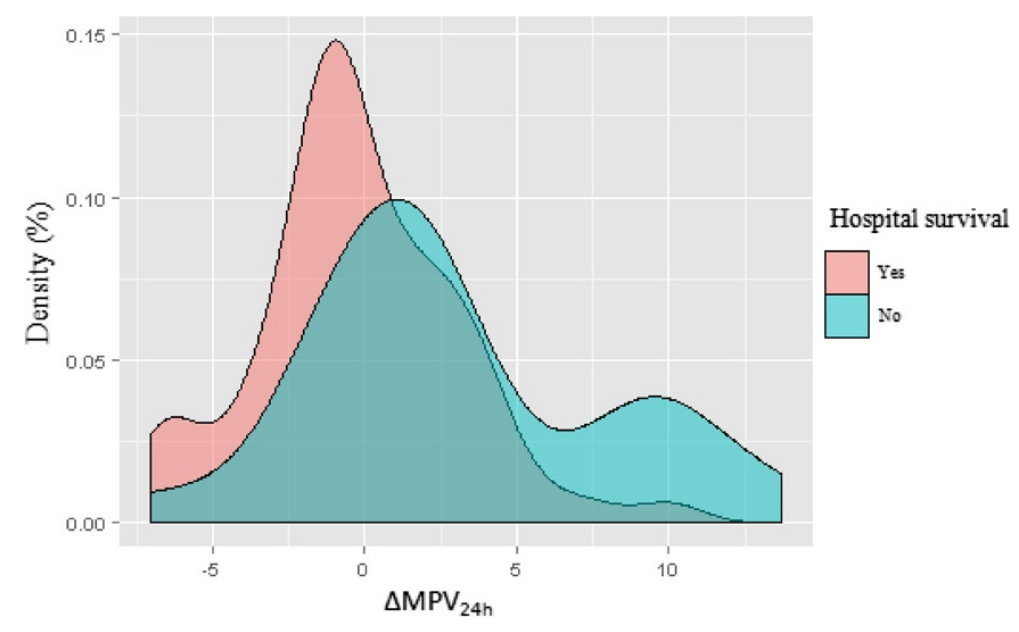

Figure 2 Density plots of mean platelet volume (MPV) values in survivors and non-survivors. 


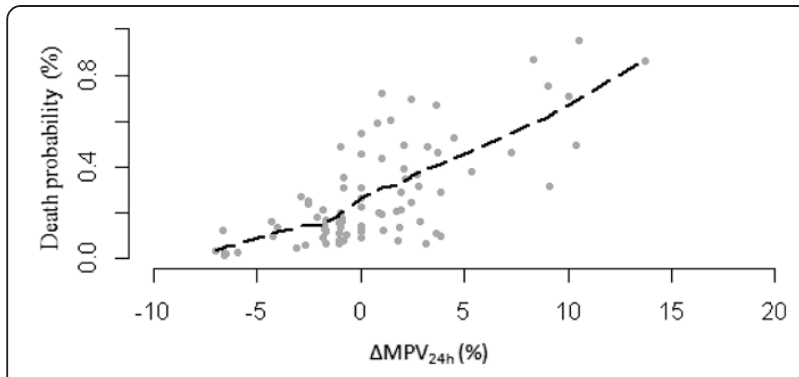

Figure 3 Plot of hospital death probability according to logistic regression analysis and $\Delta \mathrm{MPV}_{24 \mathrm{~h}}$ values. The dashed line represents the smoothed line of the plot using Friedman's 'super smoother'.

Aydemir et al. reported that increases in MPV in septic adults persist for days, being more prolonged in patients with fungal infections [18]. Becchi et al. evaluated the impact of MPV and platelet count on prognosis of critically ill septic patients and concluded that lower MPVs on admission were associated with increased mortality [6]. However, these authors also highlighted that MPV tends to increase in non-survivors and decrease in survivors, with platelet counts having an inverse trend [6]. Taken together, these findings suggest that trends in changes in MPV and platelet counts may be more reliable markers of poor prognosis than the corresponding absolute values. The discrepancies between baseline MPV values in previous reports may be

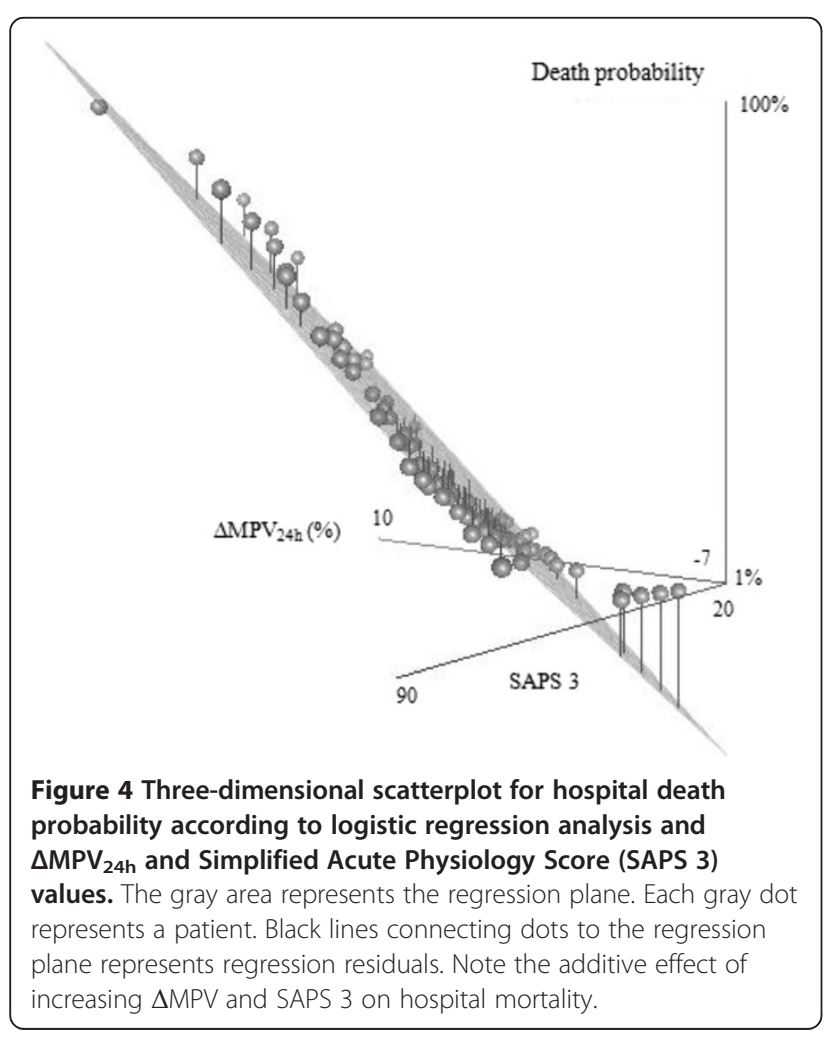

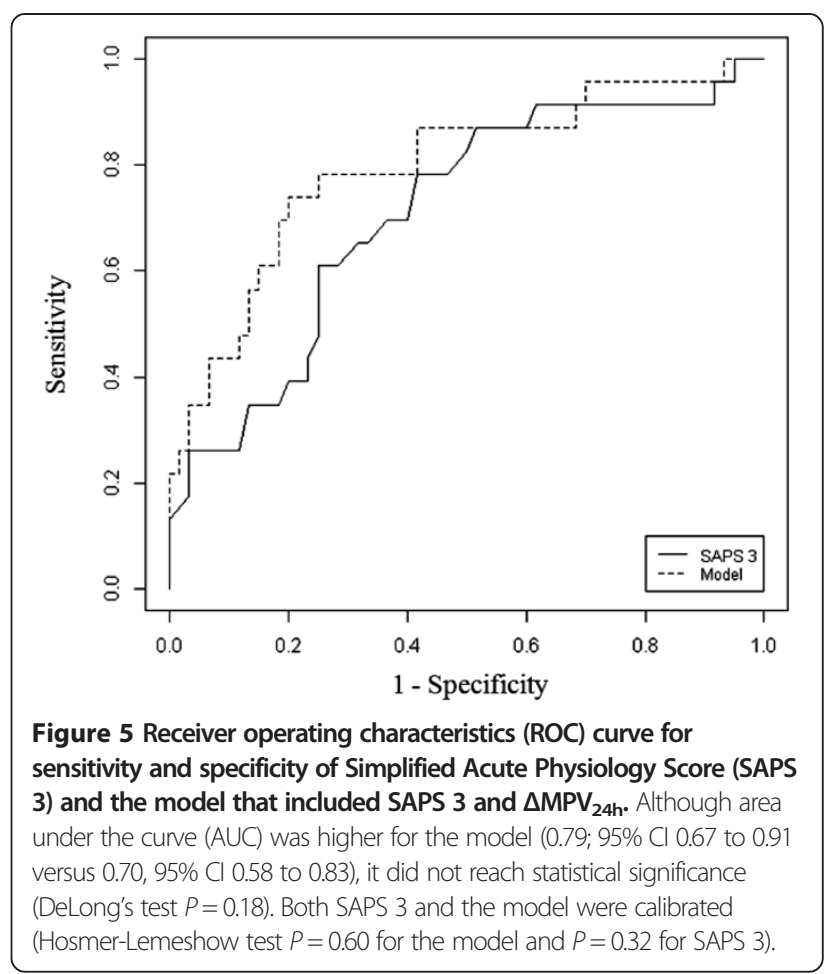

related to variations in sources of samples (septic versus non-septic, newborns versus adults) [6,7].

Because inflammation and endothelial activation are reportedly universally present in the acutely ill $[2,19]$, we tried to expand the patient groups in which changes in MPV may be relevant to prognosis by studying a broader range of critically ill patients. In our study, survivors and non-survivors had similar admission MPVs. Nevertheless, we found that patients in the $\Delta$ Plat $_{24 h} \leq 0 / \Delta M P V_{24 h}>0$ group had a higher mortality than those in the other patient groups. According to logistic regression analysis, $\Delta \mathrm{MPV}_{24 \mathrm{~h}}$ but neither $\Delta \mathrm{Plat}_{24 \mathrm{~h}}$ nor the interaction between $\Delta \mathrm{MPV}_{24 \mathrm{~h}}$ and $\Delta \mathrm{Plat}_{24 \mathrm{~h}}$ were associated with higher hospital mortality. This suggests that progressive platelet activation after the initial insult may be a marker of increasing endothelial injury, thus indicating a more severe illness [20]. There are two possible explanations for the absence of association between changes in platelet count and mortality. First, a 24-hour interval may be too short to evaluate fluctuations in platelet count during an ICU stay [5]. We therefore performed a secondary logistic regression analysis on data from the fifth day after ICU admission. The results of this analysis were similar, suggesting that the time window is not the sole factor responsible for the lack of association between changes in platelet count and mortality. Second, it is conceivable that changes in platelet count were a surrogate for changes in MPV in the previous studies $[4,5]$. In our study, even before stepwise regression, $\Delta$ Plat $_{24 \mathrm{~h}}$ was 

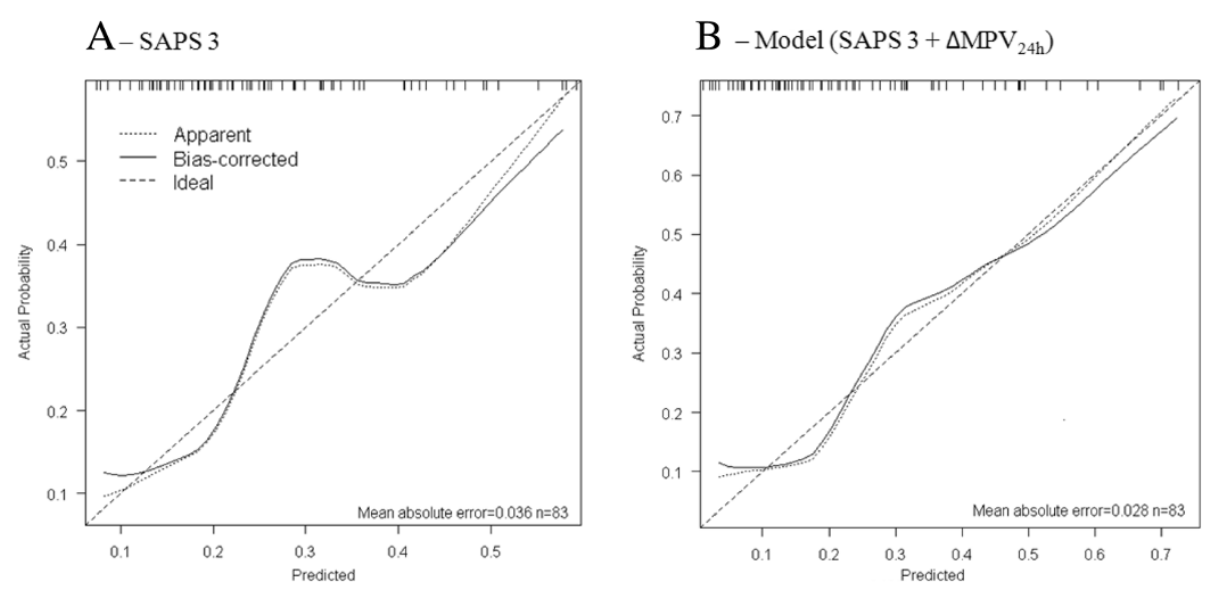

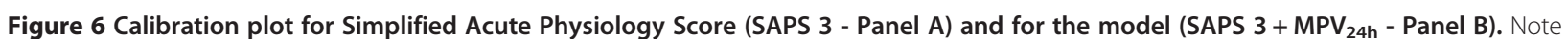
that adding $\triangle \mathrm{MPV}_{24 \mathrm{~h}}$ reduces systematic errors of SAPS 3 score on the whole range of probabilities. Mean absolute error was also smaller for the model $(0.02$ versus 0.03$)$.

not associated with hospital mortality. Another important difference between our analysis and previous studies is that we have included thrombocytopenic patients [5]. Therefore, it is conceivable that MPV is more sensitive to prognosis than platelet count when this population is taken into account.

Despite the complex and important interplay between cytokine concentrations and platelets [21], we could not find any significant differences between the four study groups in measured cytokine concentrations on ICU admission. The apparent absence of such an association may reflect the small size of our sample and the very wide distribution of cytokine values; this combination of factors could have prevented our findings from reaching statistical significance. Moreover, we did not measure direct markers of endothelial injury and activation such as adhesion molecules, von Willebrand factor and thrombomodulin, which are reportedly more closely linked to platelet activation and consumption [22]. Therefore, our failure to identify an association does not necessarily denote that reductions in platelet counts and increases in MPV are not associated with increased inflammation; rather, it could mean that other mechanisms, including endothelial injury, play a more important role [20].

Our study has several limitations. First, in similarity to previous analysis, we did not account for variations in platelet measurement essays. Platelets also display a nycthemeral variation. We tried to minimize this bias by always collecting samples at the same time during ICU admission. Being a single center study, it may have been subject to local bias. We tried to overcome the effects of small sample size and minimize type II error by performing a robust and restrictive statistical analysis. In addition, as mentioned before, the small sample size may have limited the study's power to detect differences in cytokine concentrations. We also had no data on markers of endothelial injury. Finally, the use of dynamic markers of illness severity (such as daily changes in Sequential Organ Failure Assessment (SOFA) score) could have been useful to further interpret the association

Table 2 Cytokine levels in each patient group

\begin{tabular}{|c|c|c|c|c|c|}
\hline \multirow{2}{*}{$\begin{array}{l}\text { Cytokine (pg/mL), } \\
\text { median (IQ) }\end{array}$} & \multicolumn{2}{|l|}{$\Delta$ Plat $_{24 h} \leq 0$} & \multicolumn{2}{|l|}{$\Delta$ Plat $_{24 h} \geq 0$} & \multirow[b]{2}{*}{$P$-value } \\
\hline & $\Delta \mathrm{MPV}_{24 \mathrm{~h}} \leq 0$ & $\Delta \mathrm{MPV}_{24 \mathrm{~h}} \geq 0$ & $\Delta \mathrm{MPV}_{24 \mathrm{~h}} \leq 0$ & $\Delta \mathrm{MPV}_{24 \mathrm{~h}} \geq 0$ & \\
\hline $\operatorname{IL1\beta }$ & $2.14(1.49 ; 3.91)$ & $2.07(1.49 ; 4.23)$ & $1.84(0.95 ; 5.45)$ & $2.13(1.22 ; 3.19)$ & 0.793 \\
\hline IL6 & $37.33(10.44 ; 80.23)$ & $57.43(17.64 ; 404.0)$ & $25.98(10.77 ; 55.93)$ & $40.08(10.34 ; 96.83)$ & 0.187 \\
\hline IL8 & $32.00(19.52 ; 58.75)$ & $57.14(22.34 ; 134.20)$ & $24.42(8.71 ; 65.96)$ & $40.13(30.18 ; 54.41)$ & 0.174 \\
\hline IL10 & $19.4(6.89 ; 44.03)$ & $38.41(9.41 ; 79.47)$ & $12.68(4.21 ; 25.76)$ & $9.15(6.21 ; 14.02)$ & 0.163 \\
\hline TNFa & $26.79(11.72 ; 45.42)$ & $22.62(15.81 ; 46.91)$ & $26.94(12.11 ; 33.99)$ & $19.17(11.64 ; 28.8)$ & 0.753 \\
\hline $\mathrm{IFNa}$ & $69.0(39.17 ; 95.2)$ & $62.96(52.56 ; 82.56)$ & $71.14(53.01 ; 104.3)$ & $69.01(53.15 ; 75.26)$ & 0.742 \\
\hline EGF & $158.5(127.20 ; 341.8)$ & $165.0(127.8 ; 247.8)$ & $245.5(115.2 ; 272.2)$ & $188(150.5 ; 350)$ & 0.932 \\
\hline VEGF & $188(114 ; 427.8)$ & $153(111 ; 274.2)$ & $128(80.45 ; 293.8)$ & $161(132 ; 390)$ & 0.784 \\
\hline
\end{tabular}

No post hoc analysis was performed. EGF, epidermal growth factor; VEGF, vascular endothelial growth factor. $P$-value for Kruskal-Wallis test. 
between $\triangle M P V$ and prognosis. Therefore, our results should be seen as a hypothesis-generating analysis for further prospective studies.

\section{Conclusion}

In a diverse group of critically ill patients, an increase in MPV in the first 24 hours after admission was independently associated with increased mortality. There was no significant association between inflammatory cytokine concentrations and changes in MPV and platelet count after ICU admission.

\section{Abbreviations}

COPD: chronic obstructive pulmonary disease; EGF: epidermal growth factor; IFN: Interferon; IL: Interleukin; IQ: interquartile range; MPV: Mean platlet volume; ROC: Receiver operating characteristics; SAPS: Simplified Acute Physiology Score; SOFA: Sequential Organ Failure Assessment; TNF: Tumor necrosis factor; VEGF: vascular endothelial growth factor.

\section{Competing interest}

All authors declare that they have no conflicts of interest to declare.

\section{Authors' contribution}

FGZ, HPS, FPS and LMC designed the original study. FGZ, VS and FPS collected data. OTR, FGZ and MP performed statistical analysis. HB, HPS and FPS performed cytokine measurement. FGZ, OTR, VS and MP wrote the manuscript. All authors approved the manuscript in its current form.

\section{Author details}

Intensive Care Unit, Emergency Medicine Discipline, Hospital das Clínicas, University of São Paulo, São Paulo, Brazil. ²Laboratory of Medical Investigation 51 (LIM 51), Faculty of Medicine, University of São Paulo, São Paulo, Brazil. ${ }^{3}$ Intensive Care Unit, Hospital Alemão Oswaldo Cruz, São Paulo, Brazil.

Received: 31 December 2013 Accepted: 23 May 2014

Published online: 27 June 2014

\section{References}

1. Kellum JA, Decker JM: The immune system: relation to sepsis and multiple organ failure. AACN Clin Issues 1996, 7(3):339-350. quiz 459-360.

2. Aird WC: The role of the endothelium in severe sepsis and multiple organ dysfunction syndrome. Blood 2003, 101(10):3765-3777.

3. Warkentin TE, Aird WC, Rand JH: Platelet-endothelial interactions: sepsis, HIT, and antiphospholipid syndrome. Hematology Am Soc Hematol EduC Program 2003, 2003(1):497-519.

4. Vanderschueren S, De Weerdt A, Malbrain M, Vankersschaever D, Frans E, Wilmer A, Bobbaers $\mathrm{H}$ : Thrombocytopenia and prognosis in intensive care. Crit Care Med 2000, 28(6):1871-1876.

5. Moreau D, Timsit JF, Vesin A, Garrouste-Orgeas M, de Lassence A, Zahar JR, Adrie C, Vincent F, Cohen Y, Schlemmer B, Azoulay E: Platelet count decline: an early prognostic marker in critically ill patients with prolonged ICU stays. Chest 2007, 131(6):1735-1741.

6. Becchi C, Al Malyan M, Fabbri LP, Marsili M, Boddi V, Boncinelli S: Mean platelet volume trend in sepsis: is it a useful parameter? Minerva Anestesio 2006, 72(9):749-756

7. Oncel MY, Ozdemir R, Yurttutan S, Canpolat FE, Erdeve O, Oguz SS, Uras N, Dilmen U: Mean platelet volume in neonatal sepsis. J Clin Lab Anal 2012, 26(6):493-496.

8. Gasparyan AY, Ayvazyan L, Mikhailidis DP, Kitas GD: Mean platelet volume: a link between thrombosis and inflammation? Curr Pharm Des 2011, 17(1):47-58.

9. Moreno RP, Metnitz PG, Almeida E, Jordan B, Bauer P, Campos RA, lapichino G, Edbrooke D, Capuzzo M, Le Gall JR, SAPS3 investigators: SAPS 3 - From evaluation of the patient to evaluation of the intensive care unit. Part 2: Development of a prognostic model for hospital mortality at ICU admission. Intensive Care Med 2005, 31(10):1345-1355.

10. Keppel G: Design and Analysis: A Researcher's Handbook. Prentice-Hall, Inc: Englewood Cliffs, NJ, US; 1991.
11. Ki YJ, Park S, Ha SI, Choi DH, Song H: Usefulness of mean platelet volume as a biomarker for long-term clinical outcomes after percutaneous coronary intervention in Korean cohort: a comparable and additive predictive value to high-sensitivity cardiac troponin $\mathrm{T}$ and $\mathrm{N}$-terminal pro-B type natriuretic peptide. Platelets 2013. Epub ahead of print

12. Gunebakmaz O, Kaya MG, Kaya EG, Ardic I, Yarlioglues M, Dogdu O, Kalay N, Akpek M, Sarli B, Ozdogru I: Mean platelet volume predicts embolic complications and prognosis in infective endocarditis. Int J Infect Dis 2010, 14(11):e982-e985.

13. D'Erasmo E, Aliberti G, Celi FS, Romagnoli E, Vecci E, Mazzuoli GF: Platelet count, mean platelet volume and their relation to prognosis in cerebral infarction. J Intern Med 1990, 227(1):11-14.

14. Bessman JD, Gardner FH: Platelet size in thrombocytopenia due to sepsis. Surg Gynecol Obstet 1983, 156(2):177-180.

15. Van der Lelie J, Von dem Borne AK: Increased mean platelet volume in septicaemia. J Clin Pathol 1983, 36(6):693-696.

16. Dastuque N, Picheloup F, Sie P, Genestal M, Cathala B, Boneu B: Increase in mean platelet volume in shock-related thrombocytopenia. Nouv Presse Med 1982, 11(39):2899-2901.

17. O'Connor TA, Ringer KM, Gaddis ML: Mean platelet volume during coagulase-negative staphylococcal sepsis in neonates. Am J Clin Pathol 1993, 99(1):69-71.

18. Aydemir H, Piskin N, Akduman D, Kokturk F, Aktas E: Platelet and mean platelet volume kinetics in adult patients with sepsis. Platelets 2012, Epub ahead of print.

19. Karabacak M, Dogan A, Turkdogan AK, Kapci M, Duman A, Akpinar O: Mean platelet volume is increased in patients with hypertensive crises. Platelets 2013, Epub ahead of print.

20. Levi M, van der Poll T: Endothelial injury in sepsis. Intensive Care Med 2013, 39(10):1839-1842

21. Burstein SA: Cytokines, platelet production and hemostasis. Platelets 1997, 8(2-3):93-104.

22. Reinhart K, Bayer O, Brunkhorst F, Meisner M: Markers of endothelial damage in organ dysfunction and sepsis. Crit Care Med 2002, 30(5 Suppl):S302-S312

doi:10.1186/s13613-014-0020-1

Cite this article as: Zampieri et al.: An increase in mean platelet volume after admission is associated with higher mortality in critically ill patients. Annals of Intensive Care 2014 4:20.

\section{Submit your manuscript to a SpringerOpen ${ }^{\odot}$ journal and benefit from:}

- Convenient online submission

- Rigorous peer review

- Immediate publication on acceptance

- Open access: articles freely available online

- High visibility within the field

- Retaining the copyright to your article

Submit your next manuscript at $>$ springeropen.com 